\title{
An Empirical Study on Awareness and Satisfaction of Gmail Users in Coimbatore City
}

\author{
D. Muthamizh Vendan Murugavel* \\ Associate Professor, School of Commerce and International Business, Dr. GRD College of Science, Coimbatore, India; \\ mvmgrd@gmail.com
}

\begin{abstract}
Electronic mail, most commonly referred to as email or e-mail since 1993, is a method of exchanging digital messages from an author to one or more recipients. Though there are so many email service providers in the world, Gmail has unique set of features and it is the leading email service provider at the moment in the world with huge market share. The present study primarily aims to analyse the awareness and satisfaction level of gmail users. Besides the reasons for using gmail service and switching over from previous mail services and problems faced by the gmail users were also analysed. Non-probability convenience sampling method has been used for selecting the sample respondents. Results revealed that majority of the respondents are highly aware (80\%) and also highly satisfied (70\%) with the gmail service. 'Speed' is considered as the main factor for preferring gmail service whereas 'operational difficulties' is identified as the major problem in accessing gmail service.
\end{abstract}

Keywords: Awareness, Email, Gmail, Independent Variables, Satisfaction, Service Provider

\section{Introduction}

Email is an information and communications technology. It uses technology to communicate a digital message over the Internet. Users use email differently, based on how they think about it. There are many software platforms available to send and receive. Popular email platforms include Gmail, Hotmail, rediffmail, Yahoo! Mail, Outlook and many others. The present study focuses on the major email service provider 'Gmail' by considering their dominance in this email service [1].

Gmail is a free, advertising-supported email service provided by Google. Users may access Gmail as secure webmail, as well as via POP3 or IMAP4 protocols. Gmail initially started as an invitation-only beta release on April 1, 2004 and it became available to the general public on February 7, 2007, though still in beta status at that time. The service was upgraded from beta status on July 7, 2009, along with the rest of the Google Apps suite [2].
The important Gmail features are Storage, Using attachments (Documents, Photos, Videos), Settings for personalized changes, Keyboard shortcuts in settings, Gmail Labs, MP3 Player, Tabbed inbox, Spam filter, Gmail Mobile, Social network integration, Google Voice in Gmail chat, Maximum 50 page viewer, Gmail Search, Language input, Money transfer and payment options, Importing contacts etc [3].

\section{Statement of the Problem}

Gmail is a web based mail service. The gmail cannot function without users. Hence, the satisfaction of the users with regard to the services rendered by the gmail becomes necessary. All the features of gmail should be focusing on satisfying the needs of its existing and prospecting users. So it is important to determine how the needs of the users have been awarded and satisfied. Hence, an attempt has been made in this study to know the Reasons for using

${ }^{*}$ Author for correspondence 
gmail service by the users, Awareness level of gmail users, Satisfaction level of gmail users, Reasons for switching over from previous mail services and Problems faced by the gmail users.

\section{Research Methodology}

This study is an empirical research based on the survey method. Coimbatore city in Tamil Nadu has been purposively selected for the study.

\subsection{Data}

The study is based on both primary data and secondary data. The first hand information was collected from the sample respondents with the help of an interview schedule prepared and pre-tested through pilot study. The necessary secondary data was collected from various journals, newspapers, magazines, books and websites.

\subsection{Sampling Design}

As the population size is unknown, 100 sample respondents have been selected by using non-probability convenience sampling method. Data were collected directly from the sample respondents by interviewing them personally [4].

\subsection{Area and Period of the Study}

The area of the study is confined to the Coimbatore city in Tamil Nadu. The study covered the period from September 2014 to January 2015.

\subsection{Statistical Tools Used}

The statistical tools such as Mean, Likert's scaling technique, Chi-square test and Garrett Ranking method used for this study [5].

\subsection{Reasons for using Gmail Service}

Table 1 shows the overall ranks assigned to the reasons for using Gmail service.

Table 1 reveals that Speed, Quick \& Multiple attachments and Capacity \& Storage are the major reasons for using the gmail service as per Garret ranking analysis followed by the features like Easy to operate, Availability of MP3 Player, Quick down loading process, Highly secured etc.

\subsection{Awareness Level of the Gmail Users}

Likert's 3 point rating scale is applied to measure the awareness level of the users of the Gmail service. Table

Table 1. Reasons for using Gmail service - Garrett ranking analysis

\begin{tabular}{|c|c|c|c|}
\hline Reason & Total Score & Mean Score & Rank \\
\hline Speed & 6040 & 60.40 & I \\
\hline Quick \& Multiple attachments & 5697 & 56.97 & III \\
\hline Capacity \& Storage & 5512 & 55.12 & IV \\
\hline Easy to operate & 5427 & 54.27 & V \\
\hline Availability of MP3 Player & 4978 & 49.78 & VII \\
\hline Quick down loading process & 4961 & 49.61 & VIII \\
\hline Highly secured & 4890 & 48.90 & IX \\
\hline More options & 4468 & 44.68 & X \\
\hline Chatting & 4378 & 43.78 & 31.49 \\
\hline Substitution & 3149 & & \\
\hline
\end{tabular}

Source: Computed from Primary data 
2 shows that the distribution of the total respondents by their level of awareness on Gmail service.

Table 2. Classification of sample respondents as per their level of awareness on Gmail features

\begin{tabular}{|c|c|c|}
\hline Level of Awareness & $\begin{array}{c}\text { No. of } \\
\text { Respondents }\end{array}$ & Percentage \\
\hline $\begin{array}{c}\text { Highly Aware } \\
\text { (Score above 18) }\end{array}$ & 80 & $80 \%$ \\
\hline Less Aware (Up to 18) & 20 & $20 \%$ \\
\hline Total & 100 & $100 \%$ \\
\hline
\end{tabular}

Source: Primary data

Table 2 reveals that majority of the sample respondents $(80 \%)$ are highly aware of the various gmail features.

\subsection{Association between Independent Variables and Awareness Level of Gmail Users}

Significance of the association of all the eight variables with the opinion of gmail users regarding their awareness was analysed by applying the Chi-square test. Table 3 shows the results of chi-square test.

Results of the chi-square test indicate that the independent variables such as Age, Place of residence and Browsing status have significant influence over the awareness level of the gmail users in the study region.

\subsection{Reasons for Switching Over from Previous Mail Service}

Table 4 shows the overall ranks assigned for the reasons for switching over from pervious mail service.

Table 4 reveals that More attaching \& Downloading Time, Less Operating speed and Temporary disconnection of service are the major reasons for switching over from the previous mail service to the gmail service as per Garret ranking analysis followed by the reasons like Less options, Operational difficulties etc.

\subsection{Satisfaction Level of the Gmail Users}

Likert's 5 point rating scale is applied to measure the satisfaction level of the users of the Gmail service. Table 5 shows the distribution of the total respondents by their level of satisfaction on Gmail services.

Table 5 reveals that majority of the sample respondents (70\%) are satisfied on the Gmail service and usage.

\subsection{Association between Independent Variables and Satisfaction Level of Gmail Users}

Significance of the association of all the eight variables

Table 3. Results of Chi-Square Test

\begin{tabular}{|c|c|c|c|c|}
\hline Variable & $\begin{array}{c}\text { Chi-square Calculated } \\
\text { Value }\end{array}$ & $\begin{array}{c}\text { Chi-square Table } \\
\text { Value }\end{array}$ & $\begin{array}{c}\text { Degrees of } \\
\text { Freedom }\end{array}$ & Significance \\
\hline Age & 9.4349 & 5.991 & 2 & S \\
\hline Gender & 0.3636 & 3.841 & 2 & NS \\
\hline Place of residence & 0.6491 & 5.991 & 1 & NS \\
\hline Marital status & 0.0212 & 3.841 & 1 & NS \\
\hline Educational qualification & 2.1241 & 3.841 & 3 & NS \\
\hline Occupation & 0.5939 & 7.815 & 2 & NS \\
\hline Period of using & 5.1474 & 5.991 & 3 & S \\
\hline Browsing status & 14.040 & 7.815 & & 5 \\
\hline
\end{tabular}

Level of significance 5\%; S - Significant; NS - Not Significant 
Table 4. Reasons for switching over from previous mail service - Garrett ranking analysis

\begin{tabular}{|c|c|c|c|}
\hline Reason & Total Score & Mean Score & Rank \\
\hline More attaching \& Downloading Time & 5246 & 52.46 & I \\
\hline Less Operating Speed & 5165 & 51.65 & II \\
\hline Temporary disconnection of service & 4977 & 49.77 & III \\
\hline Less options & 4897 & 48.97 & IV \\
\hline Operational difficulties & 4891 & 48.91 & V \\
\hline Lack of Awareness & 4886 & 48.86 & VI \\
\hline Lack of Security & 4738 & 47.38 & VII \\
\hline
\end{tabular}

Source: Computed from Primary data

Table 5. Distribution of sample respondents as per their level of satisfaction on Gmail service

\begin{tabular}{|c|c|c|}
\hline Level of Satisfaction & $\begin{array}{c}\text { No. of } \\
\text { Respondents }\end{array}$ & Percentage \\
\hline $\begin{array}{c}\text { Satisfied } \\
\text { (Score above 27) }\end{array}$ & 70 & $70 \%$ \\
\hline $\begin{array}{c}\text { Dissatisfied } \\
\text { (Score Up to 27) }\end{array}$ & 30 & $30 \%$ \\
\hline Total & 100 & 100 \\
\hline
\end{tabular}

Source: Primary data with the opinion of gmail users regarding their satisfaction was analysed by applying the Chi-square test. Table 6 shows the results of chi-square test.

Results of the chi-square test indicate that all the independent variables have no significant influence over the satisfaction level of the gmail users in the study region.

\subsection{Problems Faced by the Gmail Users}

Table 7 shows the overall ranks assigned to the problems faced by the Gmail users.

Table 7 portrays that Operational difficulties and Lack of Security are identified as the major

Table 6. Results of Chi-Square Test

\begin{tabular}{|c|c|c|c|c|}
\hline Variable & $\begin{array}{c}\text { Chi-square } \\
\text { Calculated Value }\end{array}$ & $\begin{array}{c}\text { Chi-square Table } \\
\text { Value }\end{array}$ & $\begin{array}{c}\text { Degrees of } \\
\text { Freedom }\end{array}$ & Significance \\
\hline Age & 5.5753 & 5.991 & 2 & NS \\
\hline Gender & 1.0840 & 3.841 & 1 & NS \\
\hline Place of residence & 5.1840 & 5.991 & 1 & NS \\
\hline Marital status & 0.1266 & 3.841 & 1 & NS \\
\hline Educational qualification & 3.1508 & 3.841 & 3 & NS \\
\hline Occupation & 1.1878 & 7.815 & 1 & NS \\
\hline Period of using & 0.1110 & 5.991 & 3 & NS \\
\hline Browsing status & 6.3260 & 7.815 & 2 & \\
\hline
\end{tabular}

Level of significance 5\%; S - Significant; NS - Not Significant 
Table 7. Problems faced by the gmail users - Garrett ranking analysis

\begin{tabular}{|c|c|c|c|}
\hline Problems & Total Score & Mean Score & Rank \\
\hline Operational difficulties & 5316 & 53.16 & I \\
\hline Lack of Security & 5253 & 52.53 & II \\
\hline Less options & 5059 & 50.59 & III \\
\hline Lack of awareness & 5074 & 50.74 & IV \\
\hline $\begin{array}{c}\text { Temporary disconnection of } \\
\text { service }\end{array}$ & 4919 & 49.19 & V \\
\hline More downloading time & 4822 & 48.22 & VI \\
\hline Less operating speed & 4370 & 43.70 & VII \\
\hline
\end{tabular}

Source: Computed from Primary data

problems of the gmail service users as per Garret ranking analysis followed by the problems like Less options, Lack of awareness etc. Less operating speed and more downloading time are considered as their least problems while using Gmail service.

\section{Suggestions}

Based on the findings of the study, the following valuable suggestions are given:

- Most of the sample respondents felt that speed is the main reason for using gmail service. Hence, it is suggested that the concerned service provider should concentrate on maintaining and increasing the speed of gmail which would attract more number of users.

- Most of the sample respondents felt that operational difficulties is the major problem while using Gmail service. Hence, it is suggested that there is a need to the gmail service provider to create awareness about various gmail features and their operation methods through YouTube videos, PPTs etc.

- It is found that $20 \%$ of the gmail users are still less aware of various features of gmail service. Hence, it is suggested that more efforts need to be taken by the gmail service provider to create awareness among the gmail users by allowing them to have online user manuals with clear explanation of all the features and their operation methods. This would help the users to learn a lot about the gmail service.

- It is found that there is a significant association between browsing status and awareness level of the respondents. Hence, it is suggested that the gmail service provider should provide many information relating to the features and operation of gmail service in the form of online advertisement whenever the users enter into the gmail website. This would certainly create and increase the level of awareness of rare as well as regular users of gmail service.

\section{Conclusion}

E-mail plays a vital role in the growth and development of the country. E-mail activity starts and ends with the users. In this modern world, rapid technological development has taken place everywhere. Email users interest and desires are also changing with the fast development of technology. To survive in this stiff competition, an email service provider has to be constantly innovating and understanding the trends and desires of the latest email users. Based on the findings of the study, some viable suggestions are given. If those are properly taken care of fruitful results could be achieved. 


\section{References}

1. Available: https://en.wikipedia.org/wiki/Gmail, retrieved on 5th February, 2015

2. Available: http://timesofindia.indiatimes.com/tech/ slideshow/9-hidden-gmail-features-you-must-know/ itslideshowviewall/43438021.cms, retrieved on 5th
February, 2015

3. Available: https://www.gmail.com/intl/en_us/mail/help/ about.html/features.html, retrieved on 2nd February, 2015

4. Kothari, C.R. "Research Methodology". Revised 2nd ed. New Delhi: Wishwa Prakashan, 2004. p.187-220.

5. Gupta. "Statistical Methods". New Delhi: Sultan Chand and Sons, 2007. p. 255-350. 